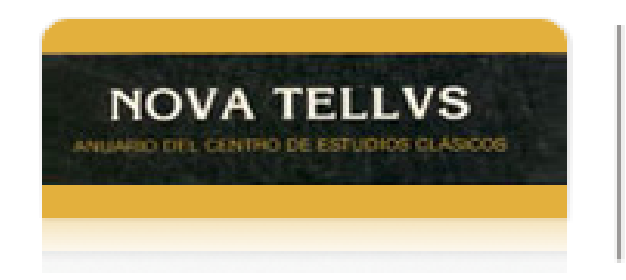

Nova Tellus

ISSN: 0185-3058

novatelu@servidor.unam.mx

Centro de Estudios Clásicos

México

Gálvez Garduño, Rafael

"Y una diosa me recibió" al volver en mi camino por el relato de Parménides

Nova Tellus, vol. 29, núm. 2, 2011, pp. 19-46

Centro de Estudios Clásicos

Distrito Federal, México

Disponible en: http://www.redalyc.org/articulo.oa?id=59122571001

- Cómo citar el artículo

- Número completo

- Más información del artículo

Página de la revista en redalyc.org

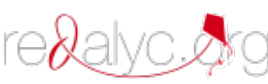

Sistema de Información Científica

Red de Revistas Científicas de América Latina, el Caribe, España y Portugal

Proyecto académico sin fines de lucro, desarrollado bajo la iniciativa de acceso abierto 


\title{
"Y una diosa me recibió" al volver en mi camino por el relato de Parménides
}

\author{
Rafael GÁlVEZ GARDUÑO \\ Universidad Nacional Autónoma de México \\ ragalgar@gmail.com
}

Resumen: Con base en algunos pasajes de Platón, se plantea la hipótesis de que los escritos de la mayoría de los filósofos presocráticos contienen un discurso insinuante e indirecto, derivado de otro fundamental y privado que contendría explícitamente su doctrina íntima. El reto que de esto resulta para el estudioso es realizar un análisis objetivo y penetrante, exento de todo prejuicio desorientador, del modo de expresión presocrático que le permita dar el "salto" del discurso público al privado e íntimo. El caso de Parménides se presenta como especialmente ejemplar, pues muestra cómo su Musa ofrece ciertas pistas e insinuaciones que, si son captadas por un lector muy atento y reflexivo, le posibilitarán acceder con claridad a ciertas intimidades del pensar parmenídeo.

\section{"And the Goddess Received Me" on my Way Back through Parmenides' Account}

ABSTRACT: Based on some passages by Plato, the author proposes that the writings of most pre-Socratic philosophers develop an insinuating and indirect discourse that derives from a private and essential one which would openly contain their deep doctrine. For the scholar, the challenge now is to carry out, in total freedom from any misleading prejudice, an objective and penetrating analysis of the pre-Socratic mode of expression, so that he or she is enabled to take the "leap" from the public discourse to the private and intimate one. Parmenide's case stands out as an especial example, as his Muse gives some clues and hints that, if captured by a very attentive and thoughtful reader, will grant him or her clear access to some inward zones of Parmenides' thought.

PALABRAS ClAVE: Filósofos presocráticos, discurso indirecto, discurso íntimo, interpretación de Parménides.

KEYWORDS: Pre-socratic philosophers, indirect discourse, intimate discourse, Parmenides' interpretation.

FECHA DE RECEPCIÓN: 8 de mayo de 2011.

FECHA DE ACEPTACIÓN: 15 de junio de 2011. 


\title{
"Y una diosa me recibió" al volver en mi camino por el relato de Parménides ${ }^{1}$
}

\author{
Rafael GÁlVEZ GARDUÑo
}

Alégrate, pues ningún hado funesto te envía a volver por este camino $[\ldots]$.

Parm., B1.26

En un pasaje del Teeteto (184a) nos dice Platón, en boca de Sócrates y refiriéndose a Parménides:

Temo que no penetremos sus palabras, y también que lo que formuló meditando nos rebase por completo.

En un pasaje del Sofista (243a7) expresa algo semejante a lo anterior, pero en un tono de disgusto y de reproche, refiriéndose a los presocráticos en general:

[...] que ellos han tenido muy poca consideración hacia nosotros, al desdeñarnos; pues cada uno prosigue sus argumentaciones hasta el fin, sin preocuparse de si los seguimos o nos han dejado atrás.

Y continúa su queja, un poco más adelante, aludiendo al modo indirecto de hablar de uno de ellos (¿Anaximandro?):

Cuando uno de ellos toma la palabra para decir que es o ha llegado a ser muchos o uno o dos, y que lo caliente está mezclado con lo frío, y en alguna otra parte supone separaciones y combinaciones, ¿comprendes tú, Teeteto, ipor los dioses!, algo de estas cosas?

Al menos en estos tres pasajes nos revela Platón su interés por penetrar el pensamiento de aquellos "grandes e ilustres antepasados" (como los llama en Sofista, 243a3-4), percibiendo agudamente en sus expresiones el deseo de presentar un texto que sólo lo plasmara oblicua e indirectamente.

\footnotetext{
${ }^{1}$ Lo que se expone en este trabajo supone lo dicho por mí en Gálvez, 2008.
} 
Para Aristóteles, en cambio, quien mostraba una completa insensibilidad a este respecto, el lenguaje presocrático era directo y "balbuciente", 2 y sólo quería ver en las doctrinas de sus antecesores torpes anticipaciones a su propio sistema.

Me parece que, más de acuerdo en esto con Platón, los primeros y grandes filósofos de Grecia realizaron una doble labor intelectual y privada, aun cuando la segunda haya tenido un efecto público: por un lado, desarrollaron un discurso claro y bien fundamentado que contenía su íntima doctrina y, por otro, dispusieron de manera estudiada una técnica expresiva que diera como producto un segundo discurso que fuera una transformación del primero. Así, por ejemplo, Anaximandro trasladaba aquella

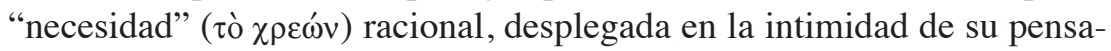
miento, de que todas las cosas retornaran a aquello que les dio origen, a una "expresión poética", como la denominó Simplicio:

[...] pues unas a las otras deben pagar pena y retribución por su injusticia, de acuerdo con los decretos del Tiempo. ${ }^{3}$

Heráclito, por su parte, además de recurrir deliberadamente a un estilo aforístico y oscuro que modificaba el de su directo y claro discurso privado, parece hacer una significativa referencia a éste cuando nos dice en el Fr. 1 (en Diels-Kranz), en un estilo que contrasta a propósito con el aforístico del resto de su libro:

Aun siendo certero este discurso, los hombres se tornan siempre incapaces de comprender antes de oírlo y al oírlo la primera vez, pues sucediendo todo según este discurso, se asemejan a inexpertos, aun cuando experimentan palabras y acciones como las que yo expongo en detalle, analizando cada cosa

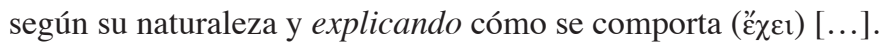

Es patente que en su libro, es decir, en su discurso público, aparte de este Fr. 1, Heráclito no analiza ni explica nada, por lo que podemos inferir de aquí que el discurso al que se refiere en esta cita es su discurso privado, en el que presentaba tales análisis y explicaciones.

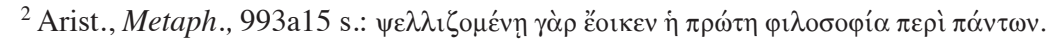

${ }^{3}$ Simp., Ph., 24, 13 ss. (12 A 9 D-K). Me parece que lo que dice Anaximandro es, no que unas a otras recíprocamente, sino que las de un género de cosas a las del género opuesto, deben pagar al fin de los tiempos pena y castigo por su injusticia. 
Y Empédocles, según Plutarco, exhorta a Pausanias, su discípulo, a que sus doctrinas las "oculte, mudo, en su corazón". 4

¿Significa esto que la doctrina que reveló secretamente a Pausanias está expuesta sólo de manera oblicua en su libro?

Un problema acuciante surge de esta visión de los filósofos presocráticos: ¿es posible, mediante un estudio objetivo y penetrante del estilo presocrático alcanzar el fondo de su pensamiento, lo que meditaron internamente (recordando la frase platónica del Teeteto), es decir, aquel discurso privado, que el texto público sólo disimula? A este respecto, el caso de Parménides es, como veremos, especialmente prometedor. Su discurso público, a todas luces parco y lacónico en su lenguaje, esconde una técnica expresiva muy depurada, basada en la insinuación y la sutileza, y va dirigido a un lector que, para detectar éstas, debe recorrerlo siendo llevado por un oído "muy atento y reflexivo", es decir, metafóricamente, por unas "yeguas" $\pi \circ \lambda u ́ \varphi \rho \alpha \sigma \tau o u .{ }^{5}$ Que la construcción de sus versos sea con frecuencia torpe no tiene importancia; lo importante está en el denso contenido significativo que hay en la construcción de sus frases, en la sutileza de su arte expresivo, que presenta aquí y allá desafíos a la inteligencia de su lector, quien debe cuidarse incluso de no caer en las trampas interpretativas a que lo predispone una lectura no muy atenta y cuidadosa. Ya hemos visto ${ }^{6}$ por ejemplo, la sutil manera como nos quiere dar a entender que el relato con el que comienza su poema es la descripción de un significativo sueño que tuvo en su primera juventud, en el que se identifica con Faetón, pero siendo ahora un nuevo Faetón "corregido y aumentado", y cómo ${ }^{7}$ este mismo relato nos presenta a un segundo narrador que interviene en él haciéndole sutiles modificaciones y añadidos con objeto de dejarlo listo para su nueva interpretación como la primera parte de un discurso filosófico. Esto muestra, como puede verse, dos distintos niveles de comunicación entre-

\footnotetext{
${ }^{4}$ Plut., Quaest. conv., VIII, 8, 1, 718e.

5 Tomando en cuenta el agudo sentido auditivo de los caballos, considero que podemos asociar, en una metáfora, el oído de un lector atento a lo que indica el texto parmení-

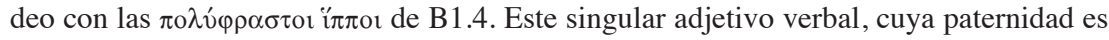
exclusiva de Parménides, pues no aparece en ningún otro texto griego antiguo, es traducido por Gómez-Lobo (1985, p. 49) como "muy atentas", atendiendo a la voz pasiva de

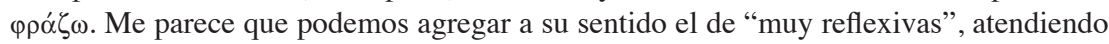
también a la voz media de dicho verbo.

${ }^{6}$ Gálvez, 2008, pp. 63 s.

${ }^{7}$ Id., pp. 66-69.
} 
lazados. Dado que me parece ser en verdad extraordinaria la manera en que logra esta doble comunicación (que el lector debe distinguir), quisiera referirme a continuación, ya no viendo el asunto analíticamente, desde el texto, sino sintéticamente, desde el punto de vista de los propósitos que guían la mano que lo confecciona, al procedimiento que me parece haber seguido el adulto Parménides para incrustar en su relato de juventud la comunicación relativa a su segunda intervención en él.

Parménides se entrega, pues, a la tarea de disponer el andamiaje expresivo que ha de permitir a un lector atento a sus sutiles insinuaciones captar este segundo nivel comunicativo. ¿Cómo lo hace? El primer paso para el arreglo de dicha disposición estaría en la presentación insinuante de su relato juvenil. Enseguida, de algún modo, tendría que mostrar en él su presencia como el adulto escritor que está interviniendo con objeto de retomarlo e insinuar que hay que darle un nuevo sentido con miras al discurso filosófico que sigue. Para ello, la única manera de hacerlo es presentarse en forma de un segundo narrador que dejara, además, entrever su intervención como posterior en el tiempo a la del primero. La dificultad que presenta esta desafiante labor artística es evidente, pero también lo es, por sus resultados, que Parménides logró su propósito. ¿Cómo lo hizo? Tenía que distinguir a un narrador del otro, haciendo, por ejemplo, que sólo el primero de ellos, el joven, narrara en primera persona los sucesos de su sueño, y mostrando al segundo asumiendo una postura distante respecto a esos mismos sucesos. Esto último lo logra de un modo muy sutil, como lo vimos en nuestro estudio anterior (cf. nota 1). Pero estas disposiciones no bastan para distinguir netamente a un narrador del otro. Había que mostrar claramente que el segundo narrador no es el mismo que narra en primera persona. Había que dejar ver que las distintas posturas que se toman en el relato no se dan por el capricho de un narrador único. ¿Cómo lograrlo? Al parecer, Parménides lo consigue al recordar una característica de los poemas homéricos, sobre todo de la Odisea: sus primeros diez versos, pronunciados por la voz del poeta, exponen un sumario de lo que va a ser relatado en voz de su Musa. Esto ya sugiere algo: presentar, a semejanza del poeta homérico, los primeros versos del relato como un extracto de lo que va a ser referido enseguida por otra voz, y hacer que ambas voces narradoras relaten por separado unos mismos sucesos, cada una asumiendo, además, su respectiva postura ante éstos. Así se resolvería el problema, pero a condición de que se le haga ver al lector que lo que está leyendo está dispuesto así. Para ello podía llamar su atención hacia el mismo objeto que atrajo la suya: los primeros versos de la Odisea. 
Parménides parece haber encontrado dos maneras de hacer esto. Una de ellas, la más sutil, fue establecer un paralelo entre su propio héroe y el homérico. Ambos poemas, el homérico y el parmenídeo, inician mencionándolo:

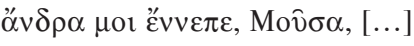

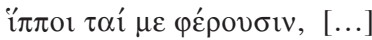

En nuestro trabajo anterior (2008, p. 62) hicimos el comentario a este paralelo, por lo que no lo repetiremos aquí. La otra fue modelar la formulación de las frases iniciales de su poema de modo que aparecieran en ellas ciertas semejanzas con las del poema homérico: ${ }^{8}$

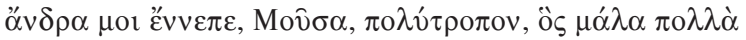

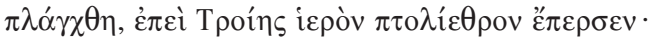

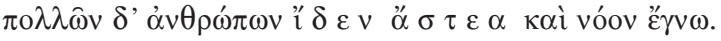

$$
\begin{aligned}
& \text { Hom., Od., I, vv. 1-3 }
\end{aligned}
$$

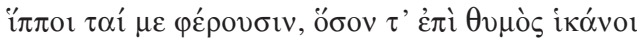

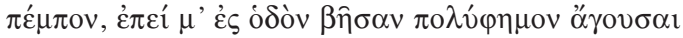

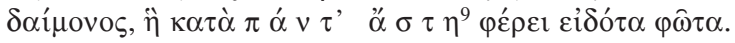

$$
\begin{aligned}
& \text { Parm., } 28 \text { B, vv. 1-3 }
\end{aligned}
$$

En efecto, en estas dos maneras de atraer la atención de su lector hacia las primeras líneas de la Odisea puede entreverse el propósito de Parménides de inducirlo a considerar los versos iniciales de su poema, es decir, el pasaje constituido por los cinco primeros versos, como un extracto del relato que sigue.

Otra de las revelaciones que Parménides se afana en insinuar a su lector es la de que el texto del "proemio", y en general de la mayoría de los pasajes del poema en su conjunto, está dispuesto de manera que se puedan

\footnotetext{
${ }^{8}$ Estas semejanzas que presentamos a continuación las hemos tomado de Mansfeld, 1964, p. 230. Con posterioridad a esta publicación, A. H. Coxon (1968, p. 69) mostró que ő́ $\sigma \tau \eta$ no está respaldada por ningún manuscrito, los cuales presentan todos la lectura corrupta $\pi \alpha v \tau^{\prime}$ ö $\tau \eta$. Pero su argumentación para rechazar ö $\sigma \tau \eta$ como una conjetura plau-

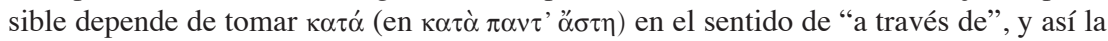
lectura "a través de todas las villas" es incompatible con B1.27, según el cual la vía es $\dot{\alpha} \pi$ '

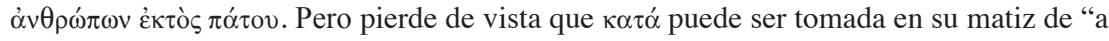
la vista de", "de cara a", con lo cual desaparece tal incompatibilidad.

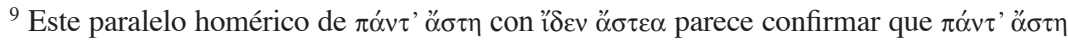
es la conjetura correcta que debe sustituir a la lectura corrupta $\pi \alpha v \tau^{\prime} \ddot{\alpha}^{\prime} \tau \eta$ de los manuscritos.
} 
descubrir en él ciertos "giros" de lectura. Para insinuar esto, introduce en primer lugar la acción de "girar" en la descripción de la apertura de las puertas (B1.19) a la vez que sustituye en ella la mención al rechinido de los ejes en sus giros alternos por la descripción de su engranaje, diciendo que están "ajustados con clavijas y pernos", con lo cual intenta despertar la atención del lector hacia ese rechinido; esto equivale a subrayarlo, a provocar que sea percibido con mayor conciencia de lo que sería mediante su explícita mención. Lo que faltaría aún sería lograr que se diera un valor simbólico a este rechinar y en general a todo el pasaje de las puertas para así insinuar que el doble "rechinido" simboliza un doble canto. Esto equivale a lograr respecto de este último pasaje lo que se deseaba lograr respecto del "proemio" en su conjunto: hacer que el lector efectuara ciertos "giros" en su lectura. Pero esto ya sería labor del propio lector en su respectivo afán de entender lo que lee. Lo más que podría intentar aún nuestro incisivo autor sería inducirlo a volver una y otra vez en su lectura hasta que ésta le revelara sus secretos, mediante frases como (B2.1): “[...] nutre el discurso tras haber escuchado". O bien (B5): "[...] Me es indiferente por dónde he de comenzar, pues ahí mismo volveré una y otra vez".

Este pasaje puede sugerir al lector parmenídeo que él mismo puede comenzar, incluso, por el pasaje de las puertas, es decir, considerarlo independientemente de la narración, como algo que hay que entender ligado a otra cosa: "Ahí están las puertas de los caminos de la Noche y del Día...".

¿A qué lugar puede referirse el "ahí" ("̌v $\theta \alpha$ ) si lo que expresa ya no está inmerso en el relato del que provenía su lectura anterior? Para que todo el verso tenga sentido hay que buscárselo, es decir, hay que dar un "giro" a su lectura. Ésta ya no corresponde a un relato. El contenido del pasaje, con excepción de lo que narran los vv. 15-17, es descriptivo, pero las puertas que describe ya no son las del relato, ya no son las significadas en la lectura anterior; sin embargo, deben ser puertas significadas por el mismo texto, pero sin trascenderlo, ya que las imágenes que sugiere ahora su lectura se encuentran ahí mismo. Se trataría, pues, de un texto cuyo contexto está en sí mismo.

Esto equivale, en cierto modo, a imaginar a Parménides entregándonos el texto de su poema a la vez que pronunciando el verso que acabamos de citar con un "movimiento de cejas", como Odiseo solía comunicarse en ocasiones con sus hombres. ${ }^{10}$ "Ahí [en el texto] están las puertas...". Ya

\footnotetext{
${ }^{10}$ Od., XII, v. 194.
} 
habíamos visto ${ }^{11}$ la interpretación de estas "puertas" como ecos que traen a la memoria frases de otros textos (la Odisea, por ejemplo) y que invitan a recorrer sus pasajes para comparar sus contextos evocativos con los de Parménides, contribuyendo así a extender y enriquecer el contenido de éstos. Ahora encontramos que podemos darles también una interpretación alternativa significando "puertas" que conforman el texto mismo, que estarían representadas por cada uno de sus pasajes o de sus expresiones, y cuya pronunciación sería el "rechinido" de una de sus "hojas", es decir, de una de sus lecturas, que evocaría una imagen o suceso. Pero, para que el recorrido del lector por el texto abriendo y atravesando sus "puertas" represente "el camino del Día", la percepción de tal "rechinido" debe estar dada por un

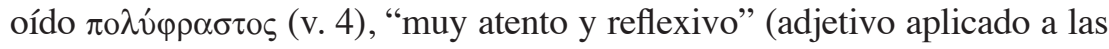
yeguas, que lo simbolizan), de lo contrario podría evocar sucesos engañosos y falsos, como muchos sueños de la Noche. En esta interpretación de las puertas cobra especial sentido el v. 14: "De ellas Díke porta las llaves que alternan [sus giros]".

Es significativa la mención de Díke, la justicia: los giros de estas "llaves" son los que hay que dar sobre ciertos vocablos de modo que, haciéndolos en un sentido, expresen lo "justo" en la interpretación literal del relato, y haciéndolo en el otro, lo "justo" en la alegórica. Un ejemplo de esto

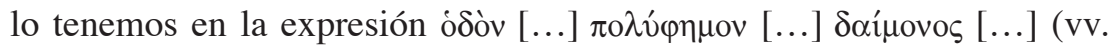
2-3). Este último término designa a una deidad de género ambivalente, y su selección es necesaria y significativa en un texto de doble interpretación si en una de ellas se trata de un dios y en la otra de una diosa. ${ }^{12}$ Como hemos visto en el otro trabajo, ${ }^{13}$ en la interpretación literal del relato su sentido "gira" hacia un dios (Helios) y en la alegórica hacia una diosa (la

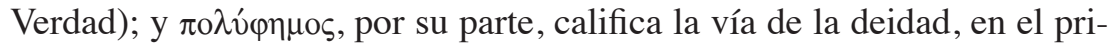
mer caso, "girando" su sentido hacia "muy famosa", y en el segundo hacia "muy discursiva". Otro ejemplo está en $\theta \varepsilon \alpha ́$ (v. 22), vocablo en el que hay que introducir una de las "llaves" de la justicia para hacer girar su sentido hacia "Aurora" en el caso de la lectura literal del texto, y hacia otra diosa (cuya identidad indagaremos más adelante) en el de la lectura alegórica.

\footnotetext{
${ }^{11}$ Gálvez, 2008, p. 79 ss.

${ }^{12}$ Habíamos afirmado en Gálvez, 2008, p. 61, que el empleo de ambigüedades como ésta revelaba el deseo de su autor de ser ambiguo a ultranza, pero esta impresión resulta de considerar sólo la lectura literal del texto.

${ }^{13}$ Gálvez, 2008, pp. 66 y 79, n. 31.
} 
De este modo, aplicando las "llaves" de la "justicia" a estos vocablos y a otros que presentan ya de entrada un sentido literal como ï $\pi$ or, ódó $\varsigma$ y 'H $\mathrm{\lambda} \uparrow{ }^{\alpha} \delta \varepsilon \varsigma$, el lector puede distinguir, como decíamos, en el texto de esta primera parte del poema un relato literal y otro alegórico. En ambos, el pasaje de las puertas evoca ya imágenes narrativas. En el primero, ya lo vimos, evoca las puertas de la Aurora, a la que seguramente nombra el joven Parménides en la descripción de su sueño. En el segundo, en cambio, el adulto pensador, que retoma su relato de juventud para agregarle el sentido alegórico que requiere su interpretación alternativa como la experiencia filosófica que lo condujo al establecimiento de su propia doctrina, es decir, hasta "el camino muy discursivo de la diosa Verdad", sustituye la frase "las puertas de la Aurora", supuestamente del relato juvenil, por "las puertas de los caminos de la Noche y del Día". Al considerar, como acabamos de ver, el pasaje de las puertas separadamente del relato, hemos aludido a esta última frase. Enseguida nos referiremos de nuevo a ella, pues al retomar dicho pasaje dentro del relato alegórico, esta expresión reaparece en un nivel más dramático. Y es que, en su esmerado propósito de conferir a su relato juvenil la posibilidad de ser tomado en un sentido alternativo, esto provocó en el pasaje B1.6-10 cierta dificultad interpretativa que, aunque se resuelve después, como veremos, ocasiona de entrada, fatalmente, alguna oscuridad y confusión en la mente del lector, para lo cual Parménides, el adulto escritor que introdujo modificaciones a su relato juvenil, tenía preparada tal frase.

La diversa lectura que de manera insinuada sugiere Parménides en muchos de los pasajes de su discurso otorga al texto una riqueza de contenido que contrasta admirablemente con la parquedad de su lenguaje, lo cual puede constatarse sobre todo en la primera parte del poema, la que conocemos como "el proemio". Hay que advertir que, como veremos, esta primera sección, en su lectura alegórica, tiene un papel central en el poema, y en este sentido sería impropio llamarlo "proemio", pues sus frases expresan en lenguaje figurado una experiencia filosófica que se conecta con pasajes como B2, B3, B6, B7 y algunos de B8, por lo que su estudio y comprensión a cabalidad es primordial para el correcto entendimiento del discurso parmenídeo en su conjunto. En relación con esto, en nuestro artículo anterior hemos llamado la atención ${ }^{14}$ hacia cierta sutileza del arte expresivo de Parménides que nos llevó a encontrar un hito en el preludio

\footnotetext{
${ }^{14}$ Id., pp. 85 ss.
} 
del pensamiento doctrinario de nuestro autor, a saber: su insinuante alusión a una crítica exhaustiva al pasaje de Jenófanes conocido como B34, y esta crítica hecha por él habría que alcanzarla nosotros, sus intérpretes, si pretendemos llegar a entender con suficiente precisión y extensión el pensamiento de nuestro filósofo.

En el presente trabajo dedicaremos una especial atención a los diez primeros versos del llamado "proemio", mejor que la ofrecida en nuestro artículo anterior, y veremos su insospechada relación con B1.28b-32, lo que nos llevará al encuentro con otro hito en la experiencia filosófica de Parménides, el que marca el arranque mismo del pensar parmenídeo. Entre estos dos hitos consideramos que está comprendida lo que podemos llamar la experiencia filosófica fundamental de nuestro filósofo, previa y preparatoria al establecimiento de su doctrina propiamente dicha.

En lo que expondremos a continuación pretendemos dar la solución definitiva a una vexata quaestio hasta hoy no resuelta, concerniente a "la determinación precisa del significado de la dóxa parmenídea y de sus relaciones con la Aletheia", para citar palabras textuales de M. Untersteiner. ${ }^{15} \mathrm{Mi}$ muy atento y reflexivo ( $\pi \mathrm{o} \lambda \hat{\varphi} \varphi \rho \alpha \sigma \tau \varsigma)$ lector juzgará si tamaña pretensión está justificada. Para ello, y ante todo, debe considerar que primordialmente, como veremos, B1 .28-32 no mira hacia delante en el texto, sino hacia atrás, hacia B1.6-10, y que la diosa parmenídea (contra lo que se piensa comúnmente) no va a revelar nada. Aparte de que la investidura propia de una divinidad sólo le permitiría revelar la Verdad y no opiniones de mortales, de las que los propios mortales podrían informarse por su cuenta, la diosa quiere poner a trabajar al "joven" a quien va dirigida su peroración. Él debe informarse de todo ( $\pi \alpha ́ v \tau \alpha \pi v \theta \varepsilon ́ \sigma \theta \alpha$ ) por sí mismo. Lo que hace Ella en la consecución de su discurso es solamente darle ciertas indicaciones prepara-

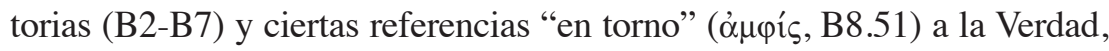
para enseguida, en la última sección, presentarle lo más característico de ciertas "opiniones mortales", aquellas que conformarían la doctrina más semejante a la verdadera (¿la de Anaximandro?), con objeto de que, juzgán-

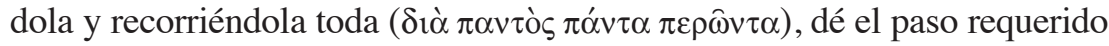
para transformarla en la Verdad "bien redonda". ${ }^{16}$

${ }^{15}$ M. Untersteiner, 1958, p. CLXVI. Este capítulo de su libro había sido publicado ya en Untersteiner, 1956, pp. 203-221.

${ }^{16}$ Que dicha doctrina sea la de Anaximandro lo sugieren, por un lado, el pasaje con que termina supuestamente la última sección del poema parmenídeo (B19), que parece evocar 
Consideremos ya la importante lectura alegórica del relato parmenídeo, que constituye en sí misma, como hemos dicho, la primera parte del propio discurso filosófico. Podemos adelantar, de entrada, como dato curioso, que hay en esta lectura cierta correspondencia con la lectura literal, la que describe el sueño del joven Parménides. Como veremos un poco más adelante, también en el ámbito de la lectura alegórica hay dos narradores; también en él uno de éstos es joven y el otro adulto; en ambos ámbitos el joven relata un sueño.

Iniciemos nuestra lectura con una paráfrasis de los cinco primeros versos, siguiendo una indicación de la "diosa" ( $\theta \varepsilon ́ \alpha, v .22)$ al "joven" (v. 24) en B2.1: "nutre ${ }^{17}$ el discurso tras haber escuchado (cada una de sus frases)": 18

Las "yeguas" (= el oído muy atento y reflexivo) que me conducen (habitualmente entre "los pasos de los hombres", v. 27), me iban enviando (en esta ocasión) tan lejos como el anhelo (de saber) alcanzaba, pues me encaminaron guiando hacia ${ }^{19}$ la vía muy discursiva de la deidad (= la Verdad $)^{20}$ que conduce al hombre que sabe ${ }^{21}$ de cara a todas las villas (o pasos de los hombres).

Por ahí (por dicha vía) era conducido (por Ella), pues por ahí me conducían las muy atentas y reflexivas "yeguas" (= el oído interior de la mente) ${ }^{22}$

el fragmento conservado del gran filósofo milesio, y, por otro, B8.5, que parece refutarlo, en esta lectura: "No era ni será alguna vez todo junto, puesto que ahora lo es".

${ }^{17}$ Quisiera llamar la atención de mi lector hacia este matiz del sentido del verbo коні́ $\omega$, que hasta ahora no ha sido tomado en cuenta, hasta donde sé, por ninguno de los intérpretes de Parménides, pues "nutrir" el discurso haciéndolo desarrollar sus potencialidades ocultas permite descubrir en él ciertas frases insospechadamente elípticas, como veremos en el caso de B2.2. Así, podríamos decir con L. Rossetti (2010, p. 194, n. 6) que llevando nuestra atención a ciertos momentos metadiscursivos del poema parmenídeo, éstos nos "ayudan a comprender mejor ciertos pasajes cruciales".

${ }^{18}$ Esta frase parentética responde de inmediato, como puede observarse, a la exhortación de "nutrir" el discurso para hacerlo crecer.

${ }^{19}$ Concuerdo con Néstor L. Cordero (1975, p. 237, n. 3) en que aquí la preposición غ̇ debe tomarse en el sentido de "hacia" y no, como es tomada generalmente, en el de "sobre" o "por".

${ }^{20}$ Que esta deidad se identifica con la Verdad está sugerido por el anhelo (de saber), el $\theta v \mu o ́ s$ del v. 1, que apuntaba a aquella "vía muy discursiva" hacia la que iban guiando las "yeguas" y que "es camino de persuasión, pues la Verdad lo sigue" (B2.4) al conducir por él "al hombre que sabe" (B1.3). Cf. Gálvez, 2008, p. 79.

${ }^{21}$ Más adelante veremos qué debe entenderse por el hombre "que sabe" o "que ha visto".

${ }^{22}$ Nótese, de pasada, que el v. 4 insinúa muy sutilmente la identidad entre la deidad del

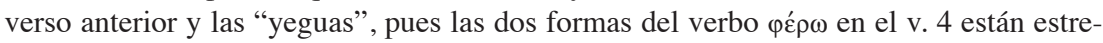


tirando del "carro" (= el pensar o el "yo"), mientras unas "jóvenes"23 dirigían el camino.

Parménides nos presenta en estos cinco primeros versos un sumario de su aventura, desde que su anhelo $(\theta v \mu o ́ s)$ de saber hace que su oído muy atento y reflexivo, que siempre lo acompaña, abandone con él el ámbito común y cotidiano en el que los hombres se debaten, para llevarlo (metafóricamente) muy lejos de ahí en su encaminamiento hacia otro ámbito, aquel en que quien habla ahora es la diosa Verdad, que lleva por su vía "muy discursiva" y elevada al hombre que "ha visto". Por esta vía era conducido por Ella, pero enseguida, sorpresivamente, esta diosa es sustituida por las "muy aten-

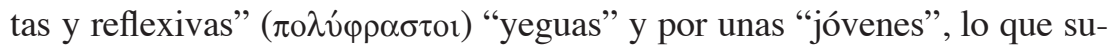
giere que Parménides quiere identificar a "yeguas" y "jóvenes" con aquélla.

A continuación (vv. 6-10) se inicia el detalle del relato con la referencia a la manera en que el "cochero" es guiado y encaminado hasta las puertas que le darán acceso a la diosa y a su divino camino:

El eje (del carro), al arder en los cubos, producía un silbido resonante (pues dos ruedas bien torneadas lo apretaban de ambos lados) cada vez que se apresuraban a enviar (a las yeguas y el carro) las jóvenes Helíades, habiendo abandonado las moradas de la noche hacia la luz, y despojándose con las manos de los velos de su cabeza.

Aquí el ő $\varepsilon$ del v. 8 no tiene el mismo "giro" que en la lectura literal, la que nos muestra el sueño del joven Parménides, en la que las "llaves" de la "justicia", girando hacia un lado, le habían dado el sentido de "mientras"; 24 ahora, girando hacia el otro, toma el sentido de "cada vez que". Por su parte, los dos primeros versos del pasaje son un excelente ejemplo del sutil ingenio de su autor al aprovechar unas mismas frases que en su literalidad sirven a un relato previo, para servir, en su sentido alegórico, al que estamos considerando ahora, pues aluden seguramente al sentido del oído, tal como lo explicaba Alcmeón de Crotona, ${ }^{25}$ a quien Parménides tal vez conocía personalmente: el carro representaría en este

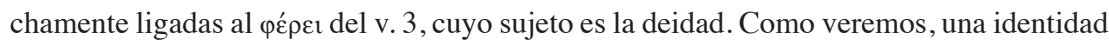
semejante se insinuará más adelante entre esta diosa y las Helíades.

${ }^{23}$ Parménides deja en suspenso, momentáneamente, la identidad de estas “jóvenes”.

${ }^{24}$ Cf. Gálvez, 2008, p. 67, n. 18.

${ }^{25}$ En Thphr., Sens., 25. 
momento la cabeza humana; las dos ruedas, las orejas, ${ }^{26}$ y el eje, el espacio interior de la cabeza entre las dos orejas, donde el aire interno resuena, como explicaba Alcmeón. Estos versos podrían interpretarse así: "El oído físico percibía un silbido resonante [...]".

Este silbido parece evocar el canto de las Sirenas que escuchó Odiseo atado al mástil de su barco, y es muy probable que esta misma evocación surgiera, con ironía, en la mente de Parménides al escuchar éste las doctrinas filosóficas de sus antecesores. Por su parte, las "moradas de la noche" (v. 9) parecen aludir al ámbito mental del conocimiento humano común y cotidiano, ${ }^{27}$ de donde se infiere que estos últimos versos del pasaje (vv. 9-10) remiten hacia atrás, hacia el inicio mismo de la aventura. La combinación de estos dos versos con la primera oración del poema (regida por

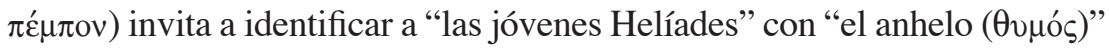
de saber, de arrancarse los "velos" que impiden ver con claridad y que son los que nublan la visión del hombre común. De este modo, las "jóvenes" que dirigen el camino de la deidad (v. 5) acompañaban también a las "yeguas" en su encaminamiento hacia la vía divina (v. 2), cuando iban enviándolas cada vez (v. 8) a escuchar (vv. 6-7) un nuevo "canto de las Sirenas". Pero esto, como puede verse, contiene una dificultad interpretativa, pues supone que encaminarse hacia la luz inherente a la vía de la Verdad se corresponde con recorrer vías por las que sólo se escuchan "sonidos estridentes", vías que no parecen llevar a la tan anhelada meta. El "joven" lector a quien va dirigido el poema parmenídeo no entiende esto. "Camina a oscuras" por su lectura. ¿Significa esto que encarna "el camino de la Noche", al que se alude en el v. 11? Tal parece que Parménides quiere sumirnos en el drama de su relato, desea que asumamos en él un papel protagónico, semejante al suyo propio. Quiere invitar a su lector a identificarse mentalmente con él, a tomar como suya su propia experiencia filosófica. Para esto, el empleo que hace, en su narración, de la primera persona del singular le cae como del cielo, pues su lector, con ello, puede sentir de pronto que es él mismo quien habla y quien relata. De buenas a primeras, resulta que hay en el relato dos narradores: el

\footnotetext{
${ }^{26}$ Ésta es también la interpretación de Sexto Empírico: Pero no es "el único detalle acertado" en ella, como decimos en Gálvez, 2008 p. 86, n. 41, ya que también lo es la de que la vía muy discursiva de la deidad es la vía de investigación de acuerdo a la razón, o bien, en terminología parmenídea, al pensar estricto.

${ }^{27}$ En Gálvez, 2008, p. 84, interpretamos las "moradas de la noche" como las "opiniones de los mortales". Me parece más precisa la que damos aquí.
} 
que lo escribe y el que lo lee: ambos narran al unísono. Pero el que lo lee, al asumir como suya esa misma experiencia sin haberla efectuado aún, está siendo inducido por su lectura a evocarla como un bello "sueño", como un ideal a alcanzar y que debe realizar conforme vaya comprendiendo lo que lee. Sin embargo, el detalle de su encaminamiento a la meta anhelada, mostrado por los vv. 6-8, presenta la dificultad señalada un poco más arriba. En efecto, ¿cómo es que se me encamina hacia el discurso verdadero mediante el paradójico procedimiento de hacerme escuchar doctrinas que pueden hechizarme y llevarme al engaño y al error? Esto hace que no comprenda mi propio relato. En otras palabras, "camino" por él "a oscuras". El que lo comprende, seguramente, es Parménides, el escritor-narrador de su propia experiencia. Él es "el hombre que sabe", que "ha visto" (દíó $\tau \alpha$, v. 3) cómo ha sido concretamente su encaminamiento, sabe lo que narra (y también lo que tal vez calla en su narración). "Camina con claridad" por su relato. Pero yo, que camino por el mío de noche, he de volver atrás en mi lectura, llevando por ella un oído "muy atento y reflexivo" para indagar si he pasado algo por alto, pero me molesta el verificar que no ha ocurrido esto. Por eso, cuando después una "diosa" me recibe (a mí, no a él) acogedoramente, intenta reanimarme diciéndome:

¡oh, joven, compañero de inmortales aurigas, que alcanzas nuestra morada con las yeguas que te conducen, alégrate!, pues ningún hado funesto te envía a volver por este camino (discursivo) [...].

Parménides, pues, encarna "el camino del Día" al transitar por su relato antes de alcanzar las "puertas" de la morada de otra diosa: la Verdad, que lo lleva a su vez por su camino, que no es otro que aquel discurso privado e íntimo del que hablábamos al comienzo de este trabajo.

Todo esto implica que el acceso a la morada de cada una de estas "diosas", la que recibe a Parménides y la que me recibe a mí, está dado por su respectiva puerta. Por esto, cuando escritor y lector relatan su arribo a estas puertas: "Ahí están las puertas de los caminos de la Noche y del Día”, nosotros, que observamos la acción narrada por uno y otro, debemos entender el verso así: "Ahí están, una al lado de la otra, la puerta del camino de la Noche y la puerta del camino del Día”.

Curiosamente, la designación de estas dos puertas (expresada por el genitivo) apunta hacia atrás, hacia los caminos que las alcanzan, no hacia lo que hay del otro lado de ellas. 
Los vv. 15-17 que presentan a las Helíades persuadiendo a Díke con engaños para que abra las puertas son un añadido que sólo tiene peso en el relato literal del sueño del joven Parménides para confirmar que dichas puertas deben tomarse como las de la Aurora, y hacer ver que las hijas de Helios, en su personalización como rayos solares, solicitan entrar para reintegrarse a su padre, que está a punto de salir para alumbrar el mundo.

Volviendo a nuestro relato, observemos que todavía ambos narradores describen al unísono la apertura de las puertas, pero al parecer el escritornarrador ha introducido una sutileza en esta descripción. Después de callar la manera como Díke las abre, parece insinuar que cada una de estas puertas se abre de manera distinta: una lo hace mediante el despliegue de sus hojas de golpe ( $\dot{\alpha} v \alpha \pi \tau \alpha \dot{\alpha} \mu \varepsilon v \alpha$, v. 18), y la otra mediante su giro alternado ( $\alpha \mu o r \beta \alpha \delta o ̀ v ~ \varepsilon i \lambda i \xi \alpha \sigma \alpha \alpha$, v. 19). Esto es muy sugestivo, ya que este segundo modo de abrirse permite escuchar el rechinido de cada hoja por separado. Esta segunda puerta sería la que alcanza Parménides, quien conoce claramente lo que ambos rechinidos simbolizan.

Como decíamos, escritor y lector "caminan" por su relato, el cual es el "camino" que recorren. Esta distinción es importante. Tal camino es el mismo para ambos, pero el recorrido por él no lo es. Éste es, para uno de ellos, un caminar claro, "el camino diurno", y para el otro, un caminar oscuro, "el camino nocturno". Por esto, cada narrador alcanza una "puerta" distinta, aquella a la que lo lleva su propio caminar, su propio "camino". Parménides, el escritor, alcanza, siguiendo su "camino diurno", la puerta que le da acceso a la diosa Verdad, quien lo lleva, a su vez, por su camino "muy discursivo", por el caminar doctrinario verdadero. Su "joven" lector alcanza, por su "camino nocturno", otra puerta, la que da acceso a otra diosa que lleva también por su camino muy discursivo, que no es otro que el poema parmenídeo, es decir, aquel discurso público del que hablábamos al principio. Por esto, a partir de su llegada ante las "puertas", ambos narradores han de separar sus relatos, al hablar de distintas puertas, distintas diosas y distintos caminos muy discursivos. Pero si su respectivo relato no entra en detalles acerca de qué puertas, diosas y caminos se trata, podrían continuarlo aún narrando al unísono. Esto pudiera ser lo que hacen después de su descripción de la apertura de las puertas (vv. 20b-21): "[...] por ahí, en fin, a través de ellas, fueron llevando las jóvenes, derecho, las yeguas y el carro por el camino".

Hay aquí, en efecto, la referencia a unas puertas, a un camino y... pero la diosa que debiera mencionarse aquí aparece sustituida por unas "jóve- 
nes", las Helíades, es decir, la visión clara de la mente. Esta diosa es, para el escritor-narrador, la Verdad, la deidad del v. 3, con lo que Parménides estaría identificando aquí nuevamente a la diosa Verdad con las Helíades. Recuérdese que antes, en el v. 4, la había identificado sutilmente con las "yeguas", es decir, con el oído muy atento y reflexivo. ${ }^{28}$ Lo anterior es muy significativo, pues Parménides, con esto, quiere sugerir a su lector que está confiriendo un carácter divino a facultades mentales capaces de conducir al anhelante de la Verdad a encontrarla. Podemos suponer que en estos versos es el escritor quien evoca el último suceso de su relato, ya que enseguida se ve que el "joven" lector no ha concluido el suyo, pues al atravesar las puertas ${ }^{29}$ procede, en su "sueño" (recuérdese), a narrar su encuentro con otra diosa (v. 22 ss.): "Y una diosa me recibió acogedoramente $[\ldots] "$.

¿Qué "diosa" es esta otra, al amparo de la cual ha colocado nuestro filósofo a su "joven" lector al alejarse de él por la vía de la Verdad? ${ }^{30}$ Ella, adivinando mi desconcierto de tener que escuchar "el canto de las Sirenas" en mi onírico encaminamiento hacia la vía de la Verdad, enseguida me explica (B1.28b-30):

[...] es necesario que te informes de todo: por un lado, del corazón imperturbable de la Verdad bien redondeada; por otro, de las opiniones de los mortales, para las que no hay una verdadera confianza.

Con lo dicho en el v. 30, la diosa confirma mi interpretación del pasaje de los vv. 6-10: las Helíades envían al oído atento a escuchar "opiniones" o doctrinas "de mortales". Pero, a la vez, en el v. 29 aporta un nuevo elemento que parece no estar previsto en el relato, ya que en dicho verso insinúa que en primer lugar hay que informarse del "corazón" de la Verdad. El relato de "mi" experiencia filosófica comienza, en el v. 6, con el segundo episodio, al que se refiere ahora el v. 30; el primero está omitido deliberadamente, y no puedo saber, por el momento, cómo he de adquirir tal información pri-

\footnotetext{
${ }^{28}$ Véase nota 22.

${ }^{29}$ Aquí el plural "puertas" estaría dado por las dos hojas de la puerta que atraviesa el "joven".

${ }^{30}$ Recuérdese que la vía de la Verdad no es una parte del poema parmenídeo, sino aquel discurso privado del que hablábamos al principio. A este respecto hay que observar que en B8.50-51 la Musa parmenídea hace una referencia al discurso y pensamiento no de la Verdad, sino en torno a ella (ó $\left.\mu \varphi i_{\varsigma}\right)$.
} 
mera. Pero aquí parece haber algo significativo: cuando la adquiera podré ya entender supuestamente por qué he de proseguir entonces a escuchar "cada vez" un distinto "canto de las Sirenas". Por ahora la diosa me exhorta a conocer todas las doctrinas establecidas, pero a la vez me previene: he de escucharlas "atado al mástil de mi barco", como Odiseo en aquel episodio homérico. Cada una de ellas, por separado, puede "hechizarme", puede convencerme de darle mi aprobación como la doctrina verdadera, pero debo desconfiar "...porque lo que aparenta era necesario que fuera realmente, al atravesar (con el pensamiento) ${ }^{31}$ todo, de un extremo al otro" (B1.31b-32).

Es decir, antes de acreditar a una de ellas como la verdadera debo probar que lo fuera, al examinarla de cabo a rabo. Con esto empiezo a vislumbrar la razón de encaminarme hacia mi meta por caminos que no parecían llevar a ella. Pero ¿cómo podría juzgar cada una de ellas? ¿Qué criterio he de manejar para distinguir lo verdadero de lo que sólo lo aparenta, lo que es de lo que no es? ${ }^{32}$

La diosa adivina mi nuevo desconcierto, pero ya no se muestra complaciente conmigo y cambia su actitud hacia mí, adoptando un talante más bien severo: “¡Vamos! ¡Yo hablaré; tú, en tanto, nutre el discurso tras haber escuchado! (es decir, tras haber dispuesto las "yeguas' y el "carro,33)" (B2.1).

Este drástico cambio de actitud me despierta de mi "sueño". Parménides me ha infundido un bello sueño, al hacerme narrar como mía su propia experiencia filosófica y hacerme también atravesar las puertas de la morada de una diosa que me acoge reanimándome a no cejar en mi intento de

\footnotetext{
${ }^{31}$ Nuevamente atendemos aquí al кó $\mu \_\alpha \iota$ de B2.1, que nos incita a descubrir elipsis insospechadas en las frases del poema. Aquí tomamos $\pi \varepsilon \rho \hat{\omega} v \tau \alpha$ como masculino, siguiendo a

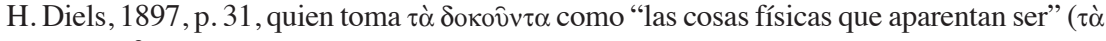

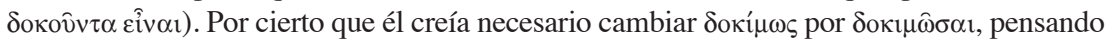

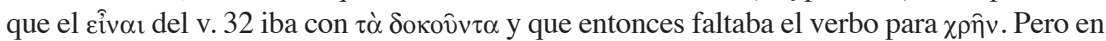
realidad tal cosa no era necesaria, pues respetando el $\delta$ оќ́ $\omega$, el pasaje puede entenderse

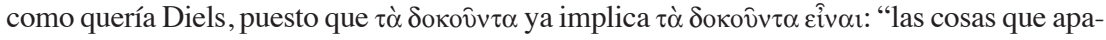
rentan (ser) era necesario que fueran realmente, al atravesar todas (con el pensamiento)". Es decir, el pensamiento las vería como son, no como nos las presenta la percepción sensorial. Esta importante elipsis tiene conexión con B4.1: "Observa, sin embargo, con el pensamiento, las cosas ausentes (al ojo que no ve, B7.4) estar firmemente presentes".

${ }^{32}$ Esto trae a la memoria B7.1: “... pues jamás se impondrá esto (al pensamiento): que sean las cosas que no son (que sólo lo aparentan)”. Nótese el sentido verídico de cỉní en esta lectura del verso.

${ }^{33}$ Esto recuerda la manera como las Helíades despiertan al joven Parménides en el relato literal de su sueño. Cf. Gálvez, 2008, p. 70.
} 
descifrar el problemático relato que aquél me impone, a interpretar lo que me ha hecho soñar. Y ahora esta diosa me despierta exhortándome al trabajo, presentándome su propia vía discursiva que debo recorrer con atención y reflexión, pues en ella me va a dar la clave para aclarar mi sueño, y me da una pista también para "caminar" exitosamente por ella: debo $\mathrm{nu}$ trir su discurso, la vía que me presenta, para hacerlo crecer y extenderse.

Pero, ¿qué diosa es esta? Ella nos recuerda a la Musa homérica (B5): "[...] Me es igual por dónde comenzar, pues ahí mismo he de volver más tarde".

Con esta expresión Parménides parece imaginar la posible respuesta de la Musa homérica al poeta, cuando éste le dice (Odisea, I, 10): "Estas cosas, diosa, hija de Zeus, cuéntanos al menos a partir de algún punto".

B5 también puede leerse, "nutriéndolo" y haciéndolo crecer, así: "[...] Me es común (con la Musa homérica) por dónde comenzar, pues ahí mismo he de volver (yo también) más tarde".

La Musa homérica comienza su relato con el episodio de Calipso y tiene que volver después para referir lo que aconteció tras la salida de su héroe de Troya, aunque en vez de esto deja que el propio Odiseo relate los sucesos anteriores a su llegada a la gruta de la ninfa. De igual modo, la Musa parmenídea comienza su relato en el v. 6 narrando también un episodio avanzado, cuando las Helíades ya van apresurándose a enviar a las yeguas a escuchar cada vez una nueva doctrina ya establecida, y debe regresar para relatar lo omitido, lo que acontece inmediatamente después de salir el "cortejo" parmenídeo del oscuro ámbito del "paso de los hombres" hacia la luz, aunque ahora ella desafía a su héroe, el "joven" lector, a relatar él esto mismo.

¿Cuál fue el episodio omitido por Parménides, inspirado por su Musa, al relatar su primera experiencia filosófica, el que precede a su empeño en escuchar "opiniones de mortales" ("cantos de las Sirenas") que no inspiran una verdadera confianza (B1.30)? ¿Qué ocurrió una vez que hubo abandonado las "moradas de la noche", el camino cotidiano marcado por

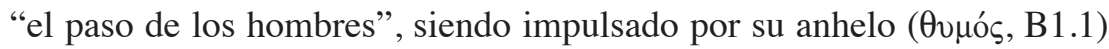
de alcanzar la Verdad? ¿Cuál es ese "corazón imperturbable” de la Verdad, que era la primera información que había que conseguir? La Musa parmenídea, que nos asiste, parece sugerírnoslo al llamarnos la atención (B1.29-30) hacia la unicidad de la Verdad en oposición a la diversidad de las doctrinas establecidas. Esto debe hacernos ver que en esta misma diversidad está el primer motivo que debe llevarnos a desconfiar de la veracidad de cada una de ellas. Y es precisamente esta diversidad lo que llamaría 
poderosamente su atención a su salida de "las moradas de la noche": en su respectivo intento por alcanzar la Verdad, otros pensadores habían llegado a presentar distintas doctrinas, como si cada uno de ellos estuviera empeñado en mostrar con la suya una realidad distinta. Pero este espectáculo entraba en conflicto con "el corazón imperturbable" de la Verdad, con el hecho incontrovertible que se imponí $a^{34}$ al pensamiento, a saber: la realidad es una sola. Y este conflicto que se presentaba ante su mente ya a la luz del día, este asombroso espectáculo, planteaba una interrogante que exigía una respuesta: ¿cómo es que, siendo la realidad única, se ha alcanzado una diversidad de doctrinas que pretenden multiplicarla? Esta pregunta, este conflicto, sería el punto de partida, el hito que marcaría el arranque mismo del pensar parmenídeo, los primeros pasos de su experiencia filosófica. La visión luminosa de tal circunstancia conflictiva y desconcertante, aunada a la respuesta del pensamiento para explicarla, constituye el primer episodio, omitido por Parménides en su relato, de su experiencia filosófica fundamental. Este primer episodio es el que la Musa parmenídea, recordando en esto a la homérica, como hemos visto, quiere hacer relatar a su "héroe", es decir, a su "joven" lector.

Hagamos, pues, el intento de seguir algunas huellas, al menos, de los primeros pasos del pensar parmenídeo: siendo la realidad una sola, también lo será la doctrina en la que aquélla esté expresada. ${ }^{35}$ Ahora bien, toda doctrina se constituye mediante el acto de pensar, por lo que si tal medio da lugar a una diversidad de doctrinas esto sólo puede deberse al empleo en ellas de diversas maneras de pensar, por lo que toda doctrina sería una particular "vía de investigación", un modo especial de conducir el pensamiento, y sólo la verdadera encerraría la manera correcta de hacerlo, sólo ella presentaría el pensar en sentido estricto, el discurrir mismo del pensar como vía, es decir, como la vía misma, la única digna de tal nombre. Hay sólo un discurrir que es un verdadero discurrir, una verda-

\footnotetext{
${ }^{34}$ Lo que expresa la Musa en B7.1 parece apuntar a este momento decisivo en el arranque mismo del pensar parmenídeo: se impone al pensamiento esta verdad fundamental (su "corazón imperturbable", como ella lo llama): la realidad es una sola; pero lo que nunca se impondrá ( $\delta \alpha \mu \eta ̣ ̂)$ a él es que sean (verdad) las cosas que no lo son, es decir, que sea (verdad)

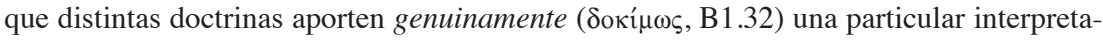
ción de aquélla, pues esto equivaldría a multiplicarla.

${ }^{35}$ Esto recuerda B8.35 ss.: “... pues, separado de lo real, (y) en lo que (éste) está expresado, no hallarás el pensar”. Aquí habla Parménides del pensar estricto, del pensar que es un discurrir que va conformando la verdadera vía, "la vía muy discursiva de la Verdad".
} 
dera vía que el pensamiento va conformando a medida que avanza por la doctrina verdadera. ${ }^{36}$ De este modo, esta doctrina se corresponde con aquella vía que "es camino de persuasión" (B2.4), la única que podría concebirse estrictamente como tal, como una vía continua que, partiendo de un principio irrevocable (que recuerda nuevamente la metáfora del "corazón imperturbable de la Verdad"), ${ }^{37}$ vaya infiriendo lo que de él se desprenda "por necesidad", formando cadenas de argumentaciones e inferencias que lleven a conformar dicha doctrina como "la Verdad bien redondeada" (B1.29); porque fuera de esto puede haber diversas maneras descuidadas de conducir el pensamiento, de discurrir, que no son un discurrir propiamente tal, que no conforman una vía discursiva consecuente, y por ello no podría ser concebida estrictamente como verdadera vía. ${ }^{38}$

Partiendo de estas consideraciones podemos entender ya que el encaminamiento parmenídeo hacia la doctrina verdadera comience por recorrer las doctrinas establecidas, pues con el criterio que acabamos de exponer es posible examinar el modo que tiene cada una de discurrir, de conducir el pensamiento, para juzgarlas y distinguir así lo verdadero de lo que sólo lo aparenta, lo que es de lo que no es.

Por otra parte, entre los prístinos comienzos del pensar parmenídeo se encuentra ya, como podemos apreciar, el concepto de "vía de investigación", que es retomado por su Musa para presentarlo explícitamente en un verso del poema en forma de frase interrogativa (B2.2): “¿Cuáles únicas vías de investigación son concebibles (en cuanto tales)?". ${ }^{39}$

${ }^{36}$ Esto habla en favor de la identidad entre el discurrir del pensar y la vía misma, y parece concordar con B3, si lo "nutrimos" consecuentemente: "pues lo mismo es pensar y ser (verdadera vía)".

${ }^{37}$ En esta segunda ocasión en que nos viene a la mente esta metáfora hay que llamar la atención a que ya no apunta al momento del espectáculo de aquella situación conflictiva que asombró a Parménides a su salida de las "moradas de la noche", sino al del inicio de su recorrido por "la vía muy discursiva de la deidad", por la verdadera vía, de la que la Musa parmenídea sólo hace indicaciones y referencias discretas a lo largo del texto del poema, como indicamos más arriba.

${ }^{38}$ La Musa hace una elocuente referencia a esto en B8.16b-18: "[ ... ] pero se ha decidido ya , por necesidad, abandonar esta [vía] impensable e innombrable (pues no es una vía verdadera), y, en cambio, [seguir] esta [otra] de modo que avance y sea realmente [una vía]”.

${ }^{39}$ Debido a la identidad que hemos visto entre "vía de investigación" y "discurrir del pensar", el uso consecutivo o final que algunos estudiosos han querido ver en el infinitivo

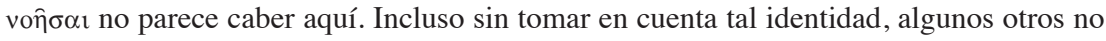


Nuestro conocimiento de lo considerado en el arranque mismo del pensamiento parmenídeo nos permite descubrir la frase que completa la pregunta así planteada: “[ ... ] y cuáles otras no lo son?”. ${ }^{4}$

Con esto se reafirma lo planteado inicialmente: hay dos géneros o familias de "vías de investigación": la que presenta la manera correcta y consecuente de conducir el pensamiento (B2.3-4) y la que lo hace (B2.5 ss.) con las distintas maneras de conducirlo defectuosamente, que no representan una verdadera conducción, una vía verdadera y real, por lo que son inconcebibles en cuanto tales, pues, (B2.7-8): "ni podrías conocer lo no real (ya que [tal conocimiento] no se cumple) ni lo expresarás $[\ldots]$ ”.

Sin embargo, el plural "vías" de B2.2 pudiera presentar alguna dificultad, pues se había hablado inicialmente sólo de una verdadera vía perfectamente concebible en cuanto tal, como el modo continuo y consecuente de dirigir el acto de pensar, pero esto se resuelve si llevamos nuestra atención a otro concepto ligado al de "vía de investigación", que está presente también en la primera etapa del pensamiento parmenídeo, y al que nos hemos referido como "cadenas" argumentativas, pues éstas serían un conjunto de "vías" particulares que contribuirían en la investigación de la Verdad para presentar ésta como un cuerpo doctrinario "bien redondeado" (B1.29) y para justificar la aparición en B2.2 del susodicho plural. Ambas cosas, el concepto de "cadenas" como lo hemos presentado y "la Verdad bien

ven en este caso aplicarse tal uso del infinitivo, al grado de que Ph. Constantineau, 1987, pp. 219-220, por ejemplo, lo combate destacando el hecho de tratarse de un infinitivo aoristo, lo que da al verbo una significación puntual y no absoluta. Pero él aplica lo puntual al tiempo limitado en que aquellas "únicas" vías pueden supuestamente concebirse o "considerarse", ya que la segunda de ellas es incognoscible (B2.7) e incluso inconcebible (B8.8 y 17). Sin embargo, me parece que hay que señalar que lo puntual en el empleo de este infinitivo aoristo está no en el limitado tiempo en que pueda "considerarse" la problemática concepción de una de ellas, sino en el acto mismo del concebirlas. Ahora bien, si la concepción de una de ellas es conflictiva, significa que algo está mal entendido entre lo que pregunta este verso 2 y lo que plantean los siguientes. $\mathrm{Y}$ es que todos los intérpretes de Parménides hemos caído en la trampa que nos ha tendido su Musa, quien nos incita a trabajar y a estar muy atentos a su insinuante discurso. En efecto, nos hemos dejado engañar imaginando que $\mu$ ôvv $\alpha$ indica sólo dos vías particulares y que ellas son las referidas en los vv. 3 y 5 . La manera correcta de entender esto, como estamos viendo en nuestro texto, da un sentido esclarecedor tanto a B2 en su conjunto como a su relación con B1.28b-32.

${ }^{40}$ Esta interpretación de B2.2, junto con una que se refiere a B8.1-3a, la expuse en una sesión con alumnos del profesor Enrique Hülsz, respondiendo a su amable invitación, el 13 de febrero de 2008. 
redonda" en cuanto cuerpo doctrinario, lo presenta también, a su manera insinuante, la Musa parmenídea en pasajes de su discurso alejados del que estamos considerando, pero no obstante estrechamente relacionados con él, como mostraremos.

El fragmento conocido como B8 comienza de esta manera: “[ ... ] Aún queda un único discurso de la vía". ${ }^{41}$

Este discurso es el único que aún queda después de abandonar los de-

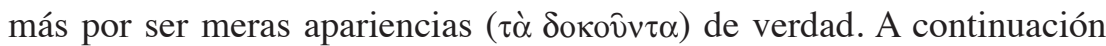
vienen dos palabras ( $\dot{\omega} \varsigma$ $̌ \sigma \tau \imath$ ) que parecen conformar una frase elíptica en la que pueden descubrirse dos lecturas complementarias:

a) (el que dice) que es.

b) puesto que (tal discurso) existe.

Ambas lecturas, que inician también una doble lectura de varios pasajes de $\mathrm{B} 8{ }^{42}$ contienen referencias a la vía de la Verdad, a aquella vía de B1.2-3 hacia la que iban guiando las "yeguas" y las Helíades, y que se identifica con el discurso íntimo y privado del que hablábamos al principio. La primera de ellas hace algunas consideraciones que atañen al contenido ontológico de dicho discurso. La segunda, en cambio, emplea esas mismas consideraciones en su aplicación al discurso mismo en cuanto tal, destacando las características que lo distinguen como el representativo de la doctrina verdadera, pues dice de él (B8.3 ss.):

${ }^{41}$ Mv̂ $\theta$ os ódoîo, la "sorprendente frase", como la llama Guthrie (1965, p. 26), pues en efecto, pudiera parecer que en ella, aparte del extraño empleo del genitivo, está invertido el orden en que se esperaban los términos "vía" y "discurso", lo que ha llevado, por cierto, a dicho estudioso a restablecerlo en su traducción, transformando, además, el caso (genitivo) en un modo verbal: "Una única vía queda aún por discurrir". Pero antes que desatender con tal proceder el verdadero sentido de una expresión ajena, me parece más prudente y conveniente estudiarla respetando la dispocisión con que la ha construido su autor. Volviendo a la construcción original de la frase, Parménides parece querer aludir a aquella vía por la que hemos sido "encaminados y guiados" (B1.2) en nuestro avanzar por ella juzgando y examinando discursos doctrinarios (cantos de las Sirenas). Tal frase podemos entenderla mejor "nutriéndola" y haciendola crecer así: "Queda aún un discurso de la vía que discurre de uno a otro de ellos hasta dejar bien definidos los lineamientos que debe presentar este para ser el único verdadero".

${ }^{42}$ Esto no debe sorprendernos si recordamos lo que habíamos apuntado acerca de la doble o diversa lectura que la Musa parmenídea quiere imprimir en muchos pasajes de su poema. 
[ ... ] puesto que, existiendo, es (algo) ingénito e imperecedero, entero, único en su género, imperturbable y completo; no era ni será alguna vez, puesto que es ahora todo junto, uno, continuo [ $\ldots$...

Este discurso verdadero tiene las propiedades de lo divino, pues, como hemos leído, es ingénito, inmortal, imperturbable, propiedades que comparte con el Ente, que es el asunto del que trata la primera lectura. Ningún otro discurso perturba a este, ninguno lo refuta. Si hay, además, alguna vez un hombre que sea el primero que lo exprese, no por ello está dando origen a algo que no existía, sólo lo está descubriendo en las potencialidades de su mente inquisitiva, al ser guiada por lo divino que mora en ella, por aquel oído $\pi \circ \lambda v ́ \varphi \rho \alpha \sigma \tau o \varsigma$ y aquella visión resplandeciente que se ha arrancado ya los "velos" (B1.10) que la cubrían cuando se movía entre "los pasos de los hombres", quienes habitan las "moradas de la noche".

Hay pasajes de B8 que no presentan esta doble lectura, como es el caso del formado por los vv. 34-41, que parecen referirse sólo al Ente parmenídeo, y como lo es también el de los que aluden únicamente a lo característico de la vía o doctrina de la Verdad, pues el que está conformado por los vv. 15-18 no es el único de éstos, ya que están incluidos en ellos también los que contienen los vv. 26-28 y 42-49, como mostraremos más abajo.

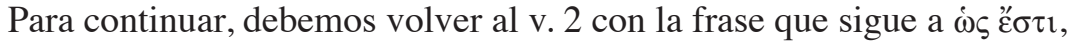
que me parece ser una frase parentética: "[ ... ] (sobre ésta hay señales muy abundantes)".

Considero que esta es una de las expresiones que la bribona Musa parmenídea ha urdido para poner a prueba el oído "muy atento y reflexivo" de su "joven" lector, ya que oculta una trampa en la que hemos caído todos nosotros, incautos intérpretes del malicioso y un tanto "perverso" 43 eléata. Para evitar caer en ella hay que dar a esta frase un sentido analéptico y no el proléptico que se le ha dado. En efecto: es sobre esta vía y no en lo que expresa el discurso que viene enseguida, en el que aparecen atributos del Ente parmenídeo que han sido identificados erróneamente con las "señales muy abundantes", donde hay que buscar éstas, pues lo muy abundante no está en aquéllos, ya que es evidente que no pueden calificarse así los ocho atributos nombrados entre el v. 3 y el 6 de B8, sino en ciertos "sig-

${ }^{43}$ Así lo llama D. Gallop, 1984, p. 4, al referirse a lo burlonas que son para él algunas ambigüedades de sintaxis que hay en el texto parmenídeo. 
nos" o "señales" textuales que se destacan sobre la vía, a todo lo largo de ella, vía que no es otra que el texto del poema que la Musa ha compuesto para que lo recorramos con nuestra lectura, y por el que podemos ir y "volver" (véc $\sigma \theta \alpha 1, \mathrm{~B} 1.26)$.

La frase textual citada la pongo entre paréntesis porque, además de en este caso sugerirlo así la partícula $\delta \dot{\varepsilon}$, considero que es independiente del seguimiento que lleva el discurso que presentan estos iniciales versos de B8, en el que el $\omega \varsigma$ del v. 3 debe leerse como la continuación directa del $\dot{\omega} \varsigma$ है $\sigma \tau \imath$ del v. 2 (no hacer esto equivale a caer en la trampa referida). Tal frase está insertada aquí por nuestra Musa no sólo para poner una sutil y "perversa" trampa a su lector, sino sobre todo, comportándose ya más

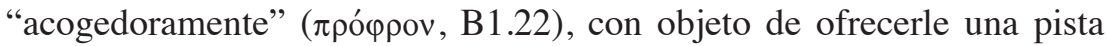
que lo auxilie en el correcto entendimiento del texto, pues los $\sigma \eta \dot{\mu} \alpha \tau \alpha$ son palabras que se destacan sobre las demás al aparecer dos veces, casi siempre en la misma posición métrica, en versos más o menos alejados uno de otro, intentando así llamar la atención del lector para incitarlo a relacionar los pasajes en que dichas palabras se encuentran, y a "nutrir" (B2.1) el contenido de uno de ellos con el del otro, aclarando de este modo su sentido. Este procedimiento es un ejemplo más de las sutilezas que presenta la técnica expresiva de nuestro sorprendente autor, ${ }^{44}$ quien está empeñado, como lo están en general los pensadores de su época, en no expresarse directamente, que era lo que les reprochaba Platón a todos ellos, como vimos al principio.

Podemos ya volver sobre el concepto de "cadenas" que habíamos encontrado en los primeros pasos del pensar parmenídeo, y al que la Musa alude de la manera insinuante que la caracteriza, pues nos dice en B8.26-28:

Por otro lado, inmutable entre los extremos de largas cadenas está sin comienzo ni término, pues la génesis y la destrucción se desviaron muy lejos (los rechazó la verdadera persuasión).

El contenido de este pasaje se refiere, pues, al discurso verdadero y a su estructura. Nos dice que está encerrado, inmutable, puesto que ningún

${ }^{44}$ En la nota 31 hemos considerado una importante e insospechada conexión entre B1.31 b-32 y B4.1, que nos llevó a descubrir la elipsis que se oculta en B1.32 $\tau \grave{\alpha} \pi \varepsilon \rho \hat{\omega} v \tau \alpha$. Esto viene ahora al caso porque tal conexión está "señalada" por nuestra acogedora diosa

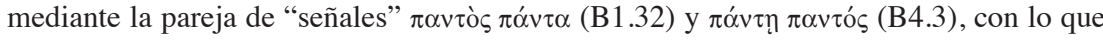
nos invita a identificar, tomado en un sentido ontológico, el contenido de B1.31b-32 con el de B4. Cf. Gálvez, 2008, p. 81, n. 36. 
otro discurso lo perturba, "entre los extremos de largas cadenas", que son aquellas "cadenas argumentativas" de que hablábamos, y que se despliegan entre un "extremo" inicial y uno final. El haber seguido ya las primeras huellas del pensamiento parmenídeo nos facilita saber cuál es ese extremo inicial de las "cadenas". Sin embargo, si no nos favoreciera esto, nuestra Musa, que nos asiste, nos ha brindado una "señal" al final del pasaje, que puede ayudarnos a investigarlo. Ahí aparece $\pi i ́ \sigma \tau \iota \varsigma \dot{\alpha} \lambda \eta \theta \dot{n} \varsigma$, que es un eco que proviene de las mismas palabras en B1.30, colocadas también al final del verso, en un pasaje que habla de "el corazón imperturbable de la Verdad bien redonda". Esta mención nos sirve para "nutrir" el verso B8.26 y empezar así a aclarar su sentido: uno de los "extremos" de tales cadenas, el inicial, sería aquel "corazón imperturbable", es decir, el principio irrevocable e irrefutable que debe fungir como punto de partida de argumentaciones e inferencias al que nos referíamos. Enseguida, el mismo pasaje que "nutre" a B8.26 sirve para alimentar al último pasaje

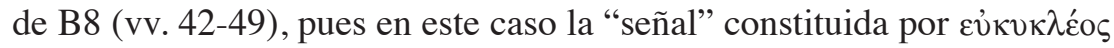

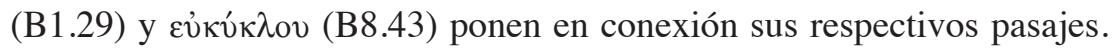
En el primero de ellos, la Verdad "bien redondeada" es contrapuesta a "las Opiniones de los mortales", contraposición que implica que tales opiniones o doctrinas no están bien redondeadas, lo que implica a su vez que la Verdad bien redondeada del verso anterior es también toda una doctrina. En el segundo se habla (v. 43) de la masa de una esfera bien redonda. La conexión entre ambos sugiere que tal imagen de una masa esférica debe aplicarse a la doctrina verdadera.

La Verdad, la doctrina verdadera, es, pues, un discurso bien redondeado, como la masa de una esfera. Aquí parece haber alguna dificultad, pues, ¿cómo puede equipararse la imagen de una esfera con la de un discurso, ya que esta última se asemeja más a una línea recta (o sinuosa, si se trata de un discurso torcido) que avanza desde su extremo inicial hasta su extremo final? Pero la Musa nos muestra cómo es esto con su característico estilo en el último pasaje de B8:

Enseguida, pues hay un extremo final, ${ }^{45}$ es [algo] completo por doquier, semejante a la masa de una esfera bien redonda, desde el centro, con igual impulso hacia todas partes, pues es necesario que ni algo más largo ni algo más corto

\footnotetext{
${ }^{45}$ También el discurso que despliega nuestra Musa en esta sección de su poema tiene un "extremo final", que es este último pasaje de B8. La frase tiene el sentido de "y para terminar...".
} 
se presente por acá o por allá; pues ni hay algo que no sea [claro ${ }^{46}$ que lo detenga de alcanzar lo igual, ni algo que sea [tan claro] de modo que sea por aquí más fuerte y por ahí más débil de lo que es [normal], pues es todo inviolable; pues igual a sí mismo por todas partes, se encuentra de la misma manera en los extremos.

En efecto, el discurso verdadero "es [algo] completo por doquier",

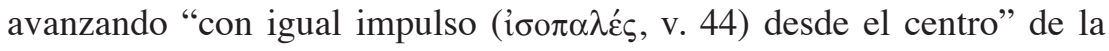
esfera "hacia todas partes", es decir, desde su punto de partida, que no es otro que aquel principio irrefutable ("corazón imperturbable de la Verdad") que es su extremo inicial, hasta su conclusión en la superficie de la "esfera", que es su extremo final. Este avance del discurso, de la argumentación, por cada uno de los "radios" ("hacia todas partes") de la "esfera" partiendo siempre del mismo principio irrevocable, va formando así cada una de sus "largas cadenas" (v. 26) que a la vez van redondeando la "masa" de la doctrina verdadera. Tales cadenas tienen todas la misma longitud, pues son impulsadas desde el único principio irrevocable con "la misma fuerza", y además, no hay, dentro de alguna cadena, algo carente de claridad (ov̉к ćóv, v. 46) que detenga en algún punto sus inferencias, impidiéndole alcanzar la igualdad en su longitud, ni tampoco algo claro (Éóv, v. 47) al grado que la haga rebasar tal medida.

El pasaje considerado no hace mención de "cadenas", que están, no obstante, implícitas en él, como puede apreciarse, y nuestra Musa, mostrándose "acogedora" con el lector que no lo advierta, quiere auxiliarlo colocando una "señal" al final del pasaje, en el v. 49: غ̇v $\pi \varepsilon i ́ \rho \alpha \sigma ı$, que es un eco del k̇v $\pi \varepsilon i ́ p \alpha \sigma r$ del v. 26, que hemos citado ya. De este modo, este verso alimenta a aquél, aclarando su sentido, quedando así: "pues igual a sí mismo por todas partes, se encuentra de la misma manera entre los extremos (de largas cadenas)".

Evoquemos nuevamente, para terminar, el "corazón imperturbable" de la doctrina verdadera, que simboliza a aquel principio irrevocable que alcanza la mente parmenídea al final de su "encaminamiento" hasta las "puertas" cuyo "rechinar" de la primera de ellas al abrirse le "revela" el susodicho principio. Su insinuante y discreta Musa lo expresa con la breve frase "que es". Nosotros, su "joven" y esforzado lector, que queremos penetrar las palabras textuales hasta su fuente originaria en el pensamiento íntimo y privado de su autor, debemos plantearnos la siguiente pregunta:

\footnotetext{
${ }^{46}$ Obsérvese que estamos dando al eón de B8.46 y 47 un sentido verídico.
} 
¿Cómo nutrir tan módica frase para descubrir todo lo que encierra? Y lo que es más dramático: ¿podremos alcanzar la talla intelectual desde la que nos mira el gran eléata para responderla a nuestra satisfacción?

\section{BIBLIOGRAFÍA}

Constantineau, Philippe, "La Question de la vérité chez Parménide", Phoenix, 41, 1987, pp. 217-240.

Cordero, Néstor L., "Notas acerca de tres pasajes del poema de Parménides", Revista Latinoamericana de Filosofía, I, 3, 1975, pp. 237-243.

Coxon, Allan H., "The text of Parmenides fr. 1. 3", Classical Quarterly, 18, 1968, p. 69.

DiEls, H, y W., Kranz, Die Fragmente der Vorsokratiker. Griechisch und Deutch, 2 vols., sexta edición revisada por W. Kranz, Berlín, Weidmann, 1952.

DiELs, Hermann, Parmenides Lehrgedicht, Berlín, G. Reimer, 1897.

Gallop, David, Parmenides of Elea: Fragments, Toronto, University of Toronto Press, 1984.

Gálvez, Rafael, "La poesía de Parménides: el arte del estilo ambiguo y desafiante, insinuador y sutil", Noua Tellus, 26-1, 2008, pp. 55-90.

Gómez-Lobo, Alfonso, Parménides, Buenos Aires, Charcas, 1985.

Guthrie, W. K. C., History of Greek Philosophy, vol. II, Cambridge, University Press, 1965

Mansfeld, Jaap, Die Offenbarung des Parmenides und die menschliche Welt, Assen, Van Gorcum, 1964.

Rossetti, Livio, "La Structure du poème de Parménide", Philosophie Antique, 10, 2010, pp. 187-226.

Untersteiner, Mario, "La dóxa en la filosofía de Parménides”, Diánoia, 2, 1956, pp. 203-221.

_, Parmenide. Testimonianze e frammenti, Florencia, La Nuova Italia, 1958. 